\title{
Simplicity, Scale, and Surprise: Evaluating Structural Form
}

\author{
Edmond P. Saliklis, M.ASCE ${ }^{1}$; Michael Bauer, S.M.ASCE ${ }^{2}$; and David P. Billington, Hon.M.ASCE ${ }^{3}$
}

\begin{abstract}
Aesthetic and ethical issues of building design are presented here to encourage meaningful discussion among today's architectural engineering students and practitioners. The evaluative aesthetic ideas of scale, simplicity, and surprise are applied to two important structures designed by Fazlur R. Khan. Khan's profound understanding of load flow in his buildings influenced his aesthetic ideas. Furthermore, his aesthetic ideas were intimately intertwined with his ethical ideas about structural logic and the role of structure in architecture. We explore these ideas and present new insights as well. Our goal is to encourage a public discourse within our profession on the topic of evaluating structural form.
\end{abstract}

CE Database subject headings: Conceptual design; Esthetics; Structural engineering; Ethics.

\section{Introduction}

This paper will critique the structural forms of two seminal buildings designed by one of the twentieth century's greatest structural engineers, Fazlur R. Khan. The first purpose of this critique is to provide aesthetic ideas and the requisite language needed by structural engineers to discuss structural form convincingly. A second purpose is to highlight some ethical issues surrounding the term "structural logic." These ethical issues will be of interest to structural engineering and architecture students, as well as to practitioners. They arise from a critique of aesthetic ideas.

\section{Structures}

The Marine Midland Bank (now One HSBC Plaza) in Rochester,

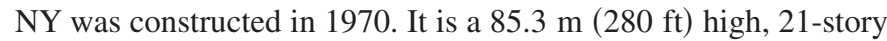
reinforced concrete building, with a unique "arching action" that is clearly visible in the lower part of the building (Fig. 1). The term "arching action" will be explained shortly. The structural system is an exterior tube with a shear wall core. The exterior columns are spaced at $1.4 \mathrm{~m}$ (4 ft $8 \mathrm{in}$.) on center with a typical

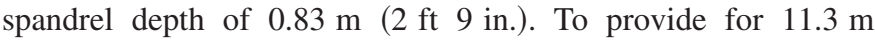
(37 ft) clear spans at ground level, seven out of every eight columns are removed. Transferring vertical load from relatively closely spaced columns in the superstructure, to the widely spaced columns at the ground level, was a problem that intrigued Khan and his colleagues at Skidmore, Owings and Merrill

\footnotetext{
${ }^{1}$ Assistant Professor, Dept. of Architectural Engineering, California Polytechnic State Univ., San Luis Obispo, CA 93407. E-mail: esalikli@calpoly.edu

${ }^{2}$ Graduate Student, Dept. of Civil and Environmental Engineering, Princeton Univ., Princeton, NJ 08544.

${ }^{3}$ Gordon Y.S. Wu Professor of Engineering, Dept. of Civil and Environmental Engineering, Princeton Univ., Princeton, NJ 08544.

Note. Discussion open until August 1, 2008. Separate discussions must be submitted for individual papers. To extend the closing date by one month, a written request must be filed with the ASCE Managing Editor. The manuscript for this paper was submitted for review and possible publication on September 11, 2006; approved on March 2, 2007. This paper is part of the Journal of Architectural Engineering, Vol. 14, No. 1, March 1, 2008. (CASCE, ISSN 1076-0431/2008/1-25-29/\$25.00.
}

(SOM). Compression flows, as if through a series of arches, above the large gaps of the ground level columns.

Two Shell Plaza is a 26-story reinforced concrete building built in 1972 in Houston, TX. Khan and his SOM colleagues, particularly the architect Bruce Graham, again solved the problem of accommodating the transition between closely and widely spaced columns in Two Shell Plaza, albeit in a way that is different than the solution for the Marine Midland Bank. Creating unique solutions to recurring structural dilemmas is a hallmark of a structural artist. The transition between the widely spaced ground floor columns and the closely spaced superstructure columns is marked by a logical transition of haunched beams and larger columns. The viewer can read the flow of compressive stresses through the resulting arch-like forms.

\section{Architectural Form, Structural Form}

Architectural form is dictated by architectural purposes, such as the practicalities of spatial organization and control of the flow of occupants. Architectural form is also concerned with the sense of space a structure creates, its symbolism, and its relationship to its setting. Structural form is dictated by structural needs, primarily to support gravity and lateral loads, and usually also the need to provide a building envelope for shelter against the elements. Carefully designed structural form can exhibit the stark beauty of controlled strength, even to the point of excitement. Structure can define the visual impact of a building, as in the case of large exposed columns, which give the appearance of strength and solidity, or the case of tall slender columns, which can create an elegant loggia effect. Architectural form can be decorative and sculptural and it often uses traditional iconographic styles, as well as proportions and details from classical antiquity. Structural form is neither decorative nor sculptural because it arises from a melding of creativity coupled with mathematical rigor and economic restraints. The ability of structural engineers to determine loads and calculate stresses in structural elements has allowed for the creation of new, elegant structural forms. Structural engineers, acting as structural artists, such as Robert Maillart, Felix Candela, and Heinz Isler, made building forms of striking appearance, while expressing purely structural engineering ideas of efficiency and economy. Fazlur Khan was also keenly aware of this inter- 


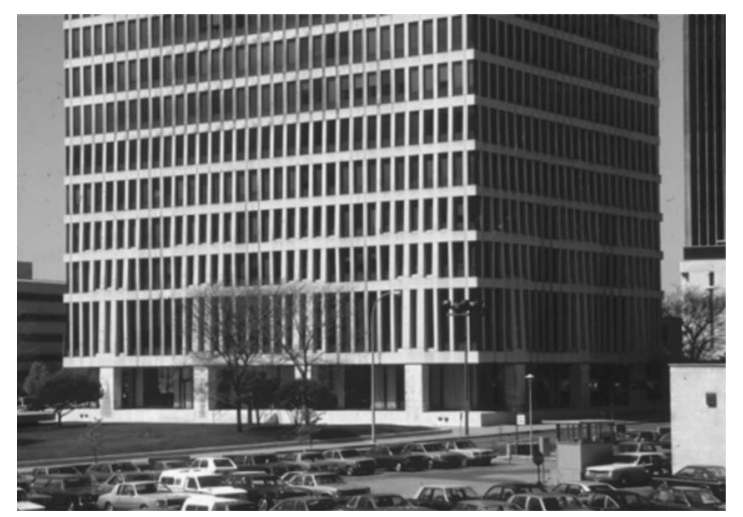

Fig. 1. Marine Midland Bank (photo by J. Wayman Williams, with permission)

play between visual impact and structural form. Furthermore, Khan was deeply concerned with the "place for structural logic in new architectural development" (Khan 1982, p. 92). Here, Khan is echoing what the great engineer/builder Pier Luigi Nervi has said about his deep respect for rational structure in architecture, his lifelong commitment to economic efficiency of structures, and the moral component of these design features. Nervi said that respecting what is structurally rational and economically prudent actually establishes the "correctness" and the "ethics" of building (Nervi 1965, p. 4). This idea of ethical design in buildings is an important one that addresses the essence of what defines great structural engineering, namely the blending of efficiency, economy, and elegance.

\section{Evaluative Aesthetic Ideas}

\section{Scale}

Structural engineers typically concern themselves with large projects. The scale of a finished project inevitably plays a role in its aesthetic impact. Some structures, such as natural draft cooling towers, are visually exciting because of their enormous scale and their hyperbolic form. However, big is not the same as beautiful, and some extremely large structures, such as high-rise buildings, must be proportioned such that they still appear elegant and inviting. For structures like these, scale can visually be a burden or a blessing.

By the 1960s, exposed structural concrete on multistory buildings was gaining acceptance. As the scale of these buildings increased, however, it became necessary for engineers to explore new structural solutions for reinforced concrete buildings. The architect Myron Goldsmith (he was also a professional engineer) was one of the first to carefully study the possibilities of visual form arising from the structural system of high-rise concrete structures. In his 1953 Master's thesis at the Illinois Institute of Technology, he explored the effects of scale on tall-building structures. Goldsmith believed that "a new structural system gives the possibility of a new architectural expression" (Goldsmith 1987, p. 22). Such a new expression became apparent in SOM's Marine Midland Bank Building in Rochester, NY, where the large opening on the ground floor was achieved through a gradual transition of load paths from the upper floors to the widely spaced ground floor columns. This ingenious structural solution conse- quently became a pronounced aspect of the façade and thus, it defines what is commonly taken as the architectural form.

Both Goldsmith and Khan were concerned with making large concrete buildings appropriately stiff for lateral loads, yet practical for construction. Y. Khan suggests that Fazlur Khan continued to develop his famous conception of the tube form with the designs of these two large concrete buildings (Khan 2004, p. 101). The Marine Midland building and Two Shell Plaza are important landmarks in the era of large scale concrete buildings. Khan was determined to reduce the cost of laterally stiffening buildings over 20 stories tall. As the scale of buildings increases, so does the need for lateral stiffness, and consequently there is a "premium for height" (Khan 2004, p. 69), which is the additional cost incurred by tall buildings. Khan enthusiastically pursued means of reducing this premium for height, and he was determined to design with the least material needed to ensure adequate lateral stiffness.

\section{Simplicity}

Another aesthetic idea that can be used to articulate aesthetics of structures is simplicity. Simplicity requires a certain elegance to be present, a flowing visual line that the viewer can follow. Both architects and sculptors sometime speak of simplicity when they critique form. For an architect, simplicity might mean neat, unobtrusive details in the building, or the practicality of neither abruptly nor arbitrarily "turning the corner" with a repetitive element such as a colonnade. For a sculptor, simplicity may mean creating an elegant silhouette from multiple viewing angles.

"Simplicity, in his (Khan's) mind, encompassed principles of proportion, harmony, and rational composition of elemental components; it did not imply plainness or absence of sophistication" (Khan 2004, p. 327). Khan firmly believed that "structure is based on a kind of reason (expressed in mathematical theories), which has its own inherent aesthetics." (Khan 1981, p. 41). Simplicity of structure means paying attention to structural details, and ensuring that the structure be as efficient as possible. He argued that "well detailed and efficient structures possess the natural elegance of slenderness and reason, and have possibly a higher value than the whims of a priori aesthetics imposed by architects who do not know how to work closely with engineers, and who do not have an inner feeling for natural structural forms" (Khan 1981, p. 41).

Khan believed that if the engineer is given the possibility of expression, this "makes the engineer more conscious of the need to design the structure as efficiently, elegantly, and articulately as possible" (Khan 1981, p. 36).

These aesthetic concerns are uniquely resolved in both the Marine Midland and the Two Shell buildings. In both of these structures, the intermediate floor columns and spandrel beams were shaped and sized according to the actual load flow. The load flow is completely understood by the master designer, and is demonstrated in Fig. 2, which is Khan's sketch of the fundamental issue of channeling the compressive stress from closely spaced columns to widely spaced ones.

In Fig. 3, a finite element representation of compressive stress is shown for a solid wall with the geometry and support intervals of the façade of Khan's 1965 Brunswick Building. If one superimposes the grid of the structural frame of the Brunswick Building, then the flow of increasing compressive forces towards the supports is seen through the gradation from light to dark, with the "arching action" indicated by the dashed lines. Khan emphasized the flow of these forces with the Marine Midland Building and Two Shell Plaza. 


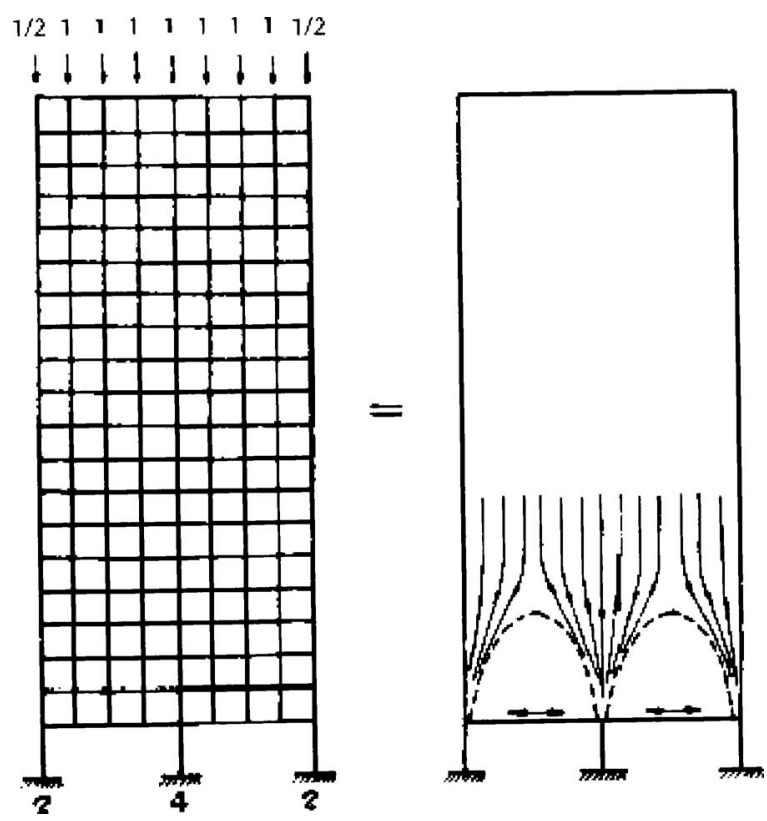

Fig. 2. Khan's sketch of load path

After completing the Brunswick building, Khan recognized that he could do away with the deep spandrel beam, and he could simply put material where it needed to be. Such a design insight was famously demonstrated by Robert Maillart on the Tavanasa Bridge, where Maillart "broke the precedent of deep spandrel walls

that came from the Roman arch bridge" tradition (Billington 1997, p. 38). The result, both for Maillart and for Khan, is a visual impression of the classical arch in traditional masonry bearing wall construction, which is the result of honest structural expression (Khan 1981, p. 38).

\section{Surprise}

It is no secret that most building design today is formulaic and standard. Structural engineers have complete command over routine designs, and aesthetic innovations come about rarely, sometimes only by the hand of master designers. One evaluative idea that can be used when judging structural form is to look for an element of surprise in the design. Are there features that de-

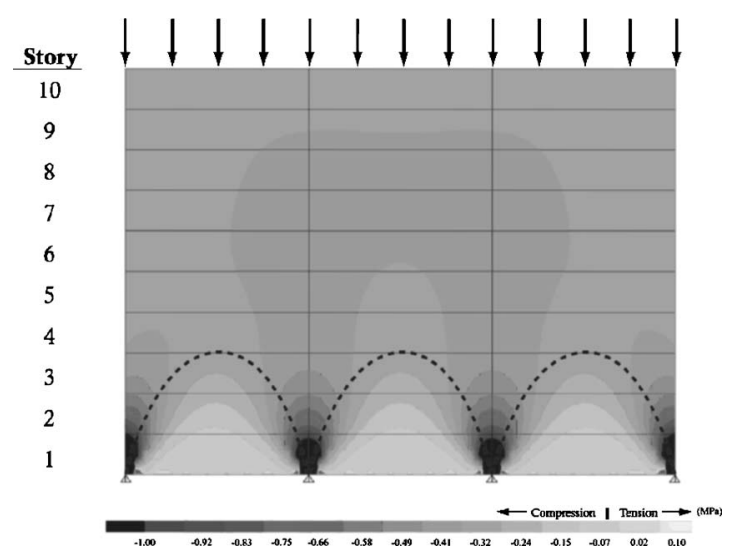

Fig. 3. Finite-element representation of compressive stress in vertical direction

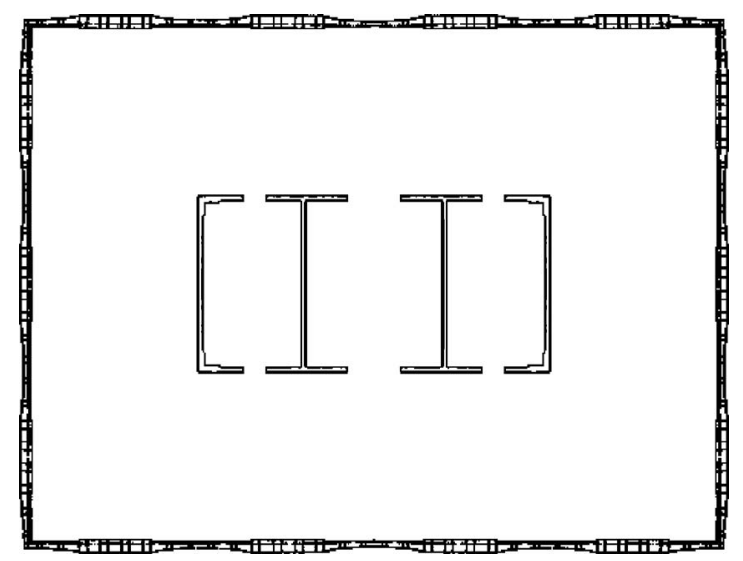

Fig. 4. Marine Midland plan view (adapted by M. Bauer from structural drawings)

light the viewer in a new and unexpected way? Is the innovation rational, yet unexpected? Such is the element of surprise.

One surprising and distinctive feature of the façade of the Marine Midland Bank is that it undulates along the vertical plane (Fig. 4). The building's architect Bruce Graham, said "we wanted to demonstrate how to make a building land" (Ali 2001, p. 91).

The variations in the surface of the façade reinvent traditional rustication. Ground level undulations of classical rustication invoke a sense of imposing strength. Khan designed the lower portion of the frame with undulating members of varying size following the arch-like load path to the widely spaced base columns. The effect of the member sizing is visually dramatic and is a clear expression of the building's gradual transfer mechanism. Yet, the effect created by Khan, is not one of grandeur, but rather, a sense of modern pragmatism.

The structural action of arches is clearly evident over the tall second story and the regular third story. A further element of surprise is introduced with the removal of the corner columns. The flow of the façade is surprisingly interrupted at the ground level corners, yet as noted by Ali, the "thin, closely spaced columns provide a visual balance with the tall lower story in the building" (Ali 2001, p. 91).

In the Two Shell Plaza building (Fig. 5), Khan surprises the viewer by emphasizing the arch action depicted in Fig. 3. Here is a graphic example of "function follows form." The designer controls the flow of the forces by making the form of the building. Khan demarcates this flow so that the viewer can understand the structure, at least on a visual, if not on an analytical level. Khan explained this idea as follows (Khan 1972):

In these two buildings the grid was analyzed for discontinuity of some of the columns at the second floor level, and the resulting forces and moments and shears were used to proportion the spandrels and columns for the first six or seven floors. These proportions were used visually, expressing the structural nature of the transfer. The result in both buildings creates a unique but otherwise recognizable pattern and form.

It is interesting to speculate how these buildings would look with today's provisions of structural integrity as called for in the American Concrete Institute's Building Code Requirements for Structural Concrete. The spirit of these code provisions is to prevent progressive collapse of the building. Although a progressive collapse analysis of these buildings is beyond the scope and 


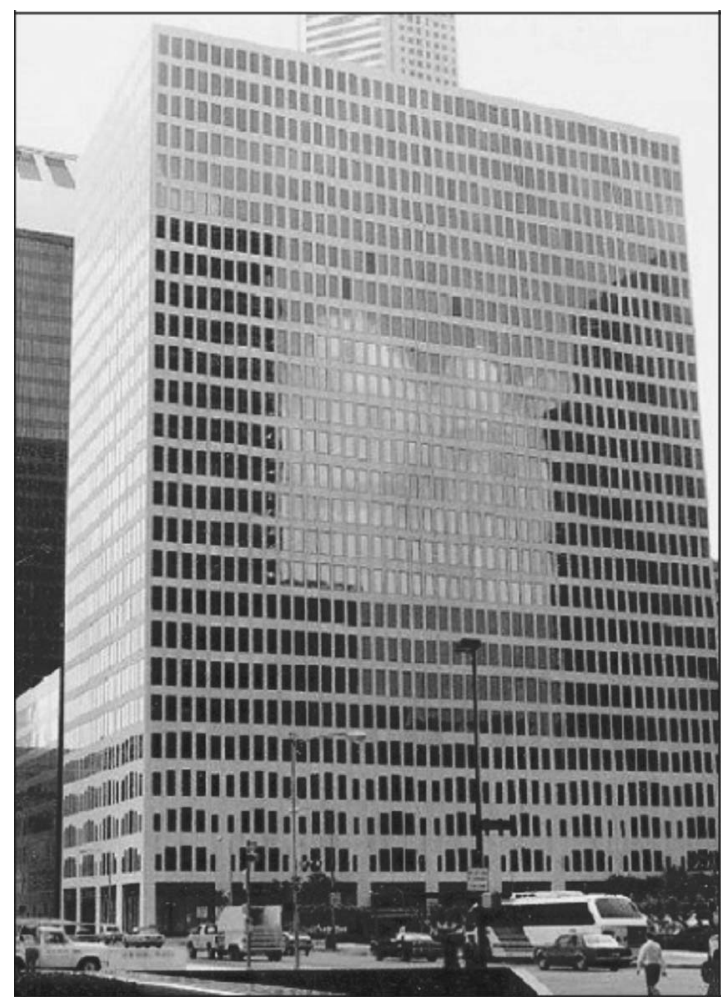

Fig. 5. Two Shell Plaza (photo by D. Billington)

focus of this paper, it is reasonable to surmise that the loss of a spandrel beam due to abnormal loads, such as an explosion, would not cause a progressive collapse. This assessment is based on inspection of Figs. 1-3, which clearly show the load flow going into the columns through the arching action. It is not the intent of ACI's Section 7.13 on structural integrity to ensure that a structure resist partial or progressive collapse caused by extreme loads, such as a terrorist attack to one of the columns.

Finite-element analyses verify this compressive flow through the arch-like pathways established by Khan. One such analysis consisted of a typical exterior portion of Two Shell Plaza near the ground level, modeled using four-node membrane elements with applied loads approximating those in the actual building. The element thickness values used to calculate stresses correspond to the frame's constant thickness of $0.36 \mathrm{~m}$ (14 in.). The base spandrel's increased thickness of $0.56 \mathrm{~m}$ (22 in.) was accounted for by means of a proportionally increased modulus of elasticity for the associated elements. The left and right sides of the model are at column centerlines, where in-plane rotation and horizontal translation were restrained to establish the appropriate boundary conditions.

Fig. 6 depicts the loading and principal stresses in the model, with arrows in the mesh indicating the relative magnitude and direction of the stresses. Applied vertical loads and base reactions are shown, while horizontal reactions from boundary constraints have been omitted. The base column compressive stress, as well as the maximum compressive and tensile stresses at the center of the base spandrel, are also indicated (positive and negative stress values indicate tension and compression, respectively). The arching action in the spandrels towards the primary column lines on either side is evident.

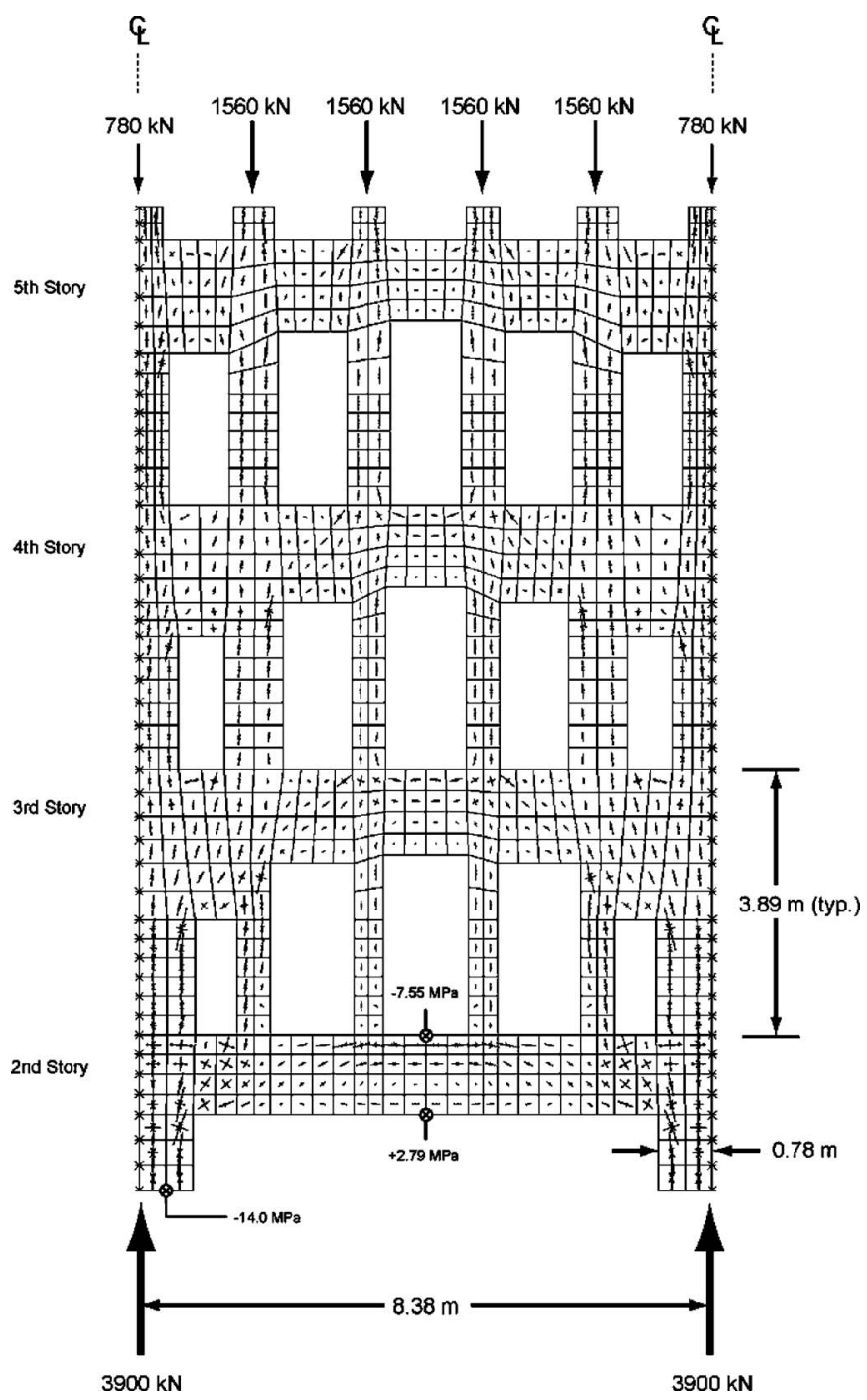

Fig. 6. Flow of compressive stresses at Two Shell Plaza

\section{Structural Logic, Public Discourse}

Architects have often hoped that progressive developments in architectural forms will have parallel beneficence in areas of quality of life and public morals. Structural artists, such as Khan, invoke public discourse by expressing the genius of their own personality, in a manner that is not architecture in the traditional sense. Structural artists "assert the freedom given to those designers that accept the disciplines of efficiency and economy and who enjoy playing with forms" (Billington 1983, p. 262). If we explore this idea in light of today's newly celebrated high-rise forms and sculptural arenas and concert halls, we are inclined to wonder whether we live in an opulent, despotic society, or a democratic, frugal one. The lavishness of high profile forms supports the idea of a rich, decadent society; one that is obsessed with consumerism.

One important source Fazlur Khan looked to for aesthetic guidance was poet and philosopher George Santayana. Yasmin Khan recounts, "One book of much interest to Fazlur... which [he read] several times was George Santayana's The Sense of Beauty." As Khan's interest in philosophy grew, "he continued to intertwine his philosophical sensibility with his practical, logical approach to life" (Khan 2004, pp. 37-38). 
Santayana argued (Arnett 1955, p. 12), that the aesthetic experience is a clue to the character of the individual having that experience. Thus, if we are thrilled by opulent buildings, it follows that our character as a society leans towards such extravagance.

Santayana also states that the "aesthetic element should not finally be abstracted from the practical and moral function of things" (Arnett 1955). The beauty of an economical structure finds resonance in the conscience of the viewer, who is concerned with stewardship of our natural resources and proper use of capital resources. Thus, the aesthetic quality of a good structural form necessarily arises within the constraints of the engineer's ethical responsibility to society (Billington 2006).

Santayana takes this thought one step further and argues that the essential right of democracy "is something purely aesthetic" (Santayana 1907, p. 85). This does not mean that democracy exhibits an aesthetic preference, but rather, that the utilitarian goodness of democracy "was receiving an aesthetic consecration" (Arnett 1955, p. 183).

\section{Conclusion}

Fazlur Khan was perhaps the greatest structural engineer of his lifetime. The care with which he designed his buildings is well known and thoroughly documented. The focus of this paper was to use several well known Khan buildings as a starting point of a discussion of aesthetics and ethical design. We chose Khan's buildings as the basis for this discussion because they were innovative at the time of their design, yet they also have exhibited permanence. These buildings are now forty years old, and although there is some spalling and local cracking, the buildings have proved to be durable and attractive testaments to the engineer's imagination. We have argued that students of structural engineering, as well as practicing professionals, can benefit from the evaluative aesthetic ideas we have presented here, namely simplicity, scale, and surprise. We urge students, faculty, and practitioners to engage in a public discourse of what constitutes appropriate and ethical design of large structures, using the arguments presented herein as a springboard for their own creative dialectic. The writers especially urge structural engineering students to study the masterworks of their own tradition.

\section{References}

Ali, M. (2001). Art of the skyscraper, the genius of Fazlur Khan, Rizzoli Int. Publications, New York.

Arnett, W. E. (1955). Santayana and the sense of beauty, Indiana Univ. Press, Bloomington, Ind.

Billington, D. P. (1983). The tower and the bridge, Basic Books, Inc., New York.

Billington, D. P. (1997). Robert Maillart: Builder, designer, and artist, Cambridge Univ. Press, Cambridge, Mass.

Billington, D. P. (2006). "Teaching ethics in engineering education through historical analysis." Sci. Eng. Ethics, 12(1), 205-222.

Goldsmith, M. (1987). Buildings and concepts, Rizzoli Int. Publications, New York.

Khan, F. (1972). "Background papers." Proc., Second National Conf. on Civil Engineering: History, Heritage, and the Humanities, J. F. Abel, ed., Princeton Univ., October 4-6, 1-19.

Khan, F. R. (1981). "Structural theories and their architectural expression-A review of possibilities." Chicago Architectural Journal, Vol. 1.

Khan, F. R. (1982). "The rise and fall of structural logic in architecture." (Khan's working paper printed posthumously). Chicago Architectural Journal, Vol. 2.

Khan, Y. S. (2004). Engineering architecture: The vision of Fazlur R. Khan, Norton, New York.

Nervi, P. L. (1965). Aesthetics and technology in building, Harvard Univ. Press, Cambridge, Mass.

Santayana, G. (1907). The sense of beauty, C. Scribner's Sons, New York. 